\title{
Considerations on the $\mathrm{H}_{2}$ desorption process for a combination reactor based on metal and complex hydrides
}

I. Bürger, M. Bhouri, M. Linder, Institute of Technical Thermodynamics, German Aerospace Center (DLR), D-70569 Stuttgart, Germany, email: inga.buerger@dlr.de

\begin{abstract}
Hydrogen storage systems based on the combination reactor concept are promising for application of future complex hydride materials with high storage capacities and low reaction kinetics at moderate operating temperatures. In such a reactor, a fast reacting metal hydride is added to a complex hydride material in a separate compartment of the tank combining the advantages of the high storage capacity of the complex hydride with the high reaction rate of the metal hydride. In the present publication, three issues regarding the desorption performance of such a reactor are discussed based on analytical considerations and 1D simulations. First, it is studied whether the optimal reactor design based on a tubular geometry that has been previously determined for the absorption reaction also enables satisfying desorption performances. It can be concluded from the corresponding simulations that based on the properties of the present reference materials $\mathrm{LaNi}_{4.3} \mathrm{Al}_{0.4} \mathrm{Mn}_{0.7}$ and $2 \mathrm{LiNH}_{2}-1.1$ $\mathrm{MgH}_{2}-0.1 \mathrm{LiBH}_{4}-3$ wt.\% $\mathrm{ZrCoH}_{3}$, the hydrogen desorption performance of the materials in this reaction geometry is good. Second, it is shown that besides the geometry of the reactor, also its module size is important, as it can be crucial for the thermal management during the desorption. A methodology was developed that allows to analytically determine a first estimate for the best minimum module size configuration - only based on the desorption rate of the basic material. This approach is confirmed by time dependent 1D simulations applying a validated model for the reference materials. Third, the influence of a realistic periodic desorption load on the performance of a combination reactor is studied. The results clearly show that since the addition of a MeH material enables much smaller module sizes, it is advantageous for the thermal management of complex hydride based reactors and increases their flexibility.
\end{abstract}

\section{Keywords}

Complex hydride, metal hydride, combination tubular reactor, modelling, desorption

\section{Introduction}

It is discussed in several scenarios of our future energy system that hydrogen can play an important role as environmental friendly energy carrier $[1,2]$. However, one bottleneck for a closed hydrogen cycle is still the efficient storage of this lightweight gas. Amongst others, one possibility is the utilization of solid state storage materials, which is a rather safe and long-term storage option. However, so far suitable materials still lead to quite heavy systems [3]. Thus, recently the focus of the application of these materials has been shifted from passenger cars to heavy duty vehicles, e.g. forklifts $[4,5]$.

Besides classical metal hydrides $(\mathrm{MeH})$ that are already considered for real-life appliations, promising solutions based on complex hydrides $(\mathrm{CxH})$ are still under investigation. These kind of materials show 
improved $\mathrm{H}_{2}$ storage capacities, thus they are in principle able to overcome the obstacle of poor gravimetric storage density common for metal hydrides [6,7]. However, these materials usually show low reaction rates at temperatures below $100{ }^{\circ} \mathrm{C}$ due to kinetic limitations of their conversion reaction with hydrogen $[8,9]$. One possibility to use the high storage capacities of these materials and to overcome their limitation in reaction dynamics is a combination reactor concept that has been presented by the authors before $[10,11]$. The idea of this concept is the combination of a fast reacting metal hydride material with a slowly reacting complex hydride material that shows a very high storage capacity. In these previous works, this concept has been presented and discussed including a model validation for the absorption and the desorption processes. Based on the validated model for two reference materials, it is now possible to investigate various suitable tank designs. E.g., in a recent study, the absorption process has been investigated and an optimal geometry for the reference materials has been defined [12]. As for motive applications the fuelling of the gas has to be very fast, the absorption process is very sensitive towards reactor geometry and material properties. Thus, it is likely that the absorption requirements will define the overall geometry of a corresponding tank. However, for technical applications, not only the absorption process, but also the desorption process has to be considered. The most common scenario for a desorption process in mobile applications is the coupling to a HT-PEM fuel cell, where the exhaust heat of the fuel cell is used in order to supply the required heat for the desorption reaction to the hydride storage material [13-15]. For complex hydrides the desorption rates at fuel cell relevant pressures $>1.7$ bar and temperatures (HT-PEM, 170 ${ }^{\circ} \mathrm{C}$ ) are usually quite low. Therefore, it is not trivial to combine high storage efficiencies (full capacity) with fast discharging dynamics in a practical application, e.g. due to heat management problems.

In the present paper, the main characteristics of a desorption process as well as the resulting challenges are discussed considering the two reference materials that have previously been used for model validation: $\mathrm{LaNi}_{4.3} \mathrm{Al}_{0.4} \mathrm{Mn}_{0.7}$, in the following abbreviated as $\mathrm{MeH}$ material, and $2 \mathrm{LiNH}_{2}-$ $1.1 \mathrm{MgH}_{2}-0.1 \mathrm{LiBH}_{4}-3 w \mathrm{w} . \% \mathrm{ZrCoH}_{3}$, in the following abbreviated as $\mathrm{CxH}$. It is obvious that with the effective storage capacities of $1.2 \mathrm{wt} . \%$ and $3.2 \mathrm{wt} . \%$ for the $\mathrm{MeH}$ and $\mathrm{CxH}$ material, a final reactor design will still not be sufficient to fulfil the system target values of the DOE for gravimetric and volumetric densities. However, for these two materials, validated models exist and the general principle of the combination reactor concept has been proven. Thus, these materials are chosen as reference materials for the present publication.

The design of the basic reactor geometry for this study has been taken from the previously published optimization process of the absorption reaction [12]. Starting from this publication, it will be first checked whether this geometry is also suitable for a generalized desorption scenario. Then in the second part, a new aspect - the module size of a modular hydride reactor - is discussed, since it influences the thermal management of the reactor and thus highly affects the desorption process (e.g., coupling to a fuel cell. In order to clarify the wording in this manuscript, the size of a module always refers to the mass of hydride that desorbs hydrogen at the same time. Furthermore, when the desorption rate is mentioned it corresponds to the effective desorption reaction rate of the pure material, while the discharging rate corresponds to the discharging process of the overall tank. 


\section{I.Bürger et al.}

Finally, in the third part, more realistic dynamic operation scenarios are discussed. Therefore, the basic model is extended to capture the $\mathrm{MeH}$ reabsorption process of hydrogen during low load conditions.

\section{Model formulation}

\subsection{Geometry}

For modelling purposes, in this paper a simple axisymmetric 1D geometry has been applied that represents the cylindrical shape of a tube-shaped reactor, compare Figure 1 and [12]. The metal hydride material is located in the center with a radius $r_{\mathrm{MeH}}=d_{\mathrm{MeH}}$. In the annulus of the tube, the complex hydride is inserted and the thickness of this layer can be varied corresponding to the ratio $\xi=$ $d_{\mathrm{CxH}} / d_{\mathrm{MeH}}$. The resulting volumetric fraction of the $\mathrm{CxH}$ material is referred to as $\varepsilon_{\mathrm{C} \times \mathrm{H}}=V_{\mathrm{CxH}} / V_{\text {total }}$. Both materials are separated by a gas permeable separation layer (GPSL). As this layer consists of a thin stainless steel mesh, the heat and mass transfer resistances at this boundary are negligible. The thickness of the stainless steel wall $d_{\mathrm{S} . \mathrm{S}}$ separating the hydride container from the heat transfer fluid is considered according to the following equation [12]

$$
d_{\mathrm{S} . \mathrm{S}}=\frac{2 r_{o}}{1+\frac{20}{S} \frac{K}{P} v},
$$

where $r_{0}$ is the external diameter of the stainless steel tube and $P$ is the maximum applied pressure. The remaining parameters have been taken for stainless steel 1.4571 at a maximum temperature of $250{ }^{\circ} \mathrm{C}$ : design strength $K=186 \mathrm{Nmm}^{-2}$, safety factor $S=1.5$ and the utilization factor of the allowable design stress $v=0.065$. The geometries used for simulations in this study are summarized in Table 1.

\subsubsection{Model equations}

For the presented simulations, the model is implemented into the FEM software COMSOL Multiphysics and rate equations, the mass balance of the gas as well as the total energy balance are considered for the metal hydride and the complex hydride domains. For the steel wall, only an energy balance of the solid is considered. The values for the respective properties as well as all assumptions can be taken from the previous publication, where this model has been validated [11].

The rate equations can be written as

$$
\frac{\partial X}{\partial t}=r_{\mathrm{R}}
$$

where $X$ is the transformed fraction, $r_{\mathrm{R}}$ is the effective reaction rate for the materials as function of temperature and pressure given in $\mathrm{s}^{-1}$. The corresponding equations are summarized in the following Equations 3-5. More details can be found in $[10,11,16]$.

Desorption of the $\mathrm{CxH}$ material $(\mathrm{Li}-\mathrm{Mg}-\mathrm{N}-\mathrm{H}), 1^{\text {st }}$ step, $0<X_{\mathrm{l}}<0.67$ :

$$
r_{\mathrm{R}, \mathrm{des}, \mathrm{CXH}, \mathrm{I}}=\frac{\partial X_{\mathrm{I}}}{\partial t}=2.35 \cdot 10^{12}\left[\mathrm{~s}^{-1}\right] \cdot \exp \left(\frac{-131800\left[\mathrm{Jmol}^{-1} \mathrm{~K}^{-1}\right]}{\Re T T}\right) \cdot 1.5\left(1-X_{\mathrm{I}}\right)\left[-\ln \left(1-X_{\mathrm{I}}\right)\right]^{0.33} \cdot \ln \left(\frac{P_{\mathrm{eq}}}{P}\right)
$$

Desorption of the $\mathrm{CxH}$ material $(\mathrm{Li}-\mathrm{Mg}-\mathrm{N}-\mathrm{H}), 2^{\text {nd }}$ step, $0.67<X_{\| 1}<1$ :

$$
r_{\mathrm{R}, \mathrm{des}, \mathrm{CXH}, \mathrm{II}}=\frac{\partial X_{\mathrm{II}}}{\partial t}=3.044 \cdot 10^{15}\left[\mathrm{~s}^{-1}\right] \cdot \exp \left(\frac{-161400\left[\mathrm{Jmol}^{-1} \mathrm{~K}^{-1}\right]}{\Re T}\right) \cdot\left(1-\frac{0.001515}{w t_{\max } \cdot 0.33}(P-1.1[\mathrm{bar}])\right)
$$

Desorption of the MeH material: 
I.Bürger et al.

$$
r_{\mathrm{R}, \mathrm{des}, \mathrm{MeH}}=\frac{\partial X}{\partial t}=20\left[\mathrm{~s}^{-1}\right] \cdot \exp \left(\frac{-16500\left[\mathrm{Jmol}^{-1} \mathrm{~K}^{-1}\right]}{\Re T}\right) \cdot(1-X) \cdot \ln \left(\frac{P_{\mathrm{eq}}}{P}\right) .
$$

Absorption of the $\mathrm{MeH}$ material:

$$
r_{\mathrm{R}, \mathrm{abs}, \mathrm{MeH}}=\frac{\partial X}{\partial t}=100\left[\mathrm{~s}^{-1}\right] \cdot \exp \left(\frac{-21000\left[\mathrm{Jmol}^{-1} \mathrm{~K}^{-1}\right]}{\Re T}\right) \cdot(1-X) \cdot\left(\frac{P-P_{\mathrm{eq}}}{P_{\mathrm{eq}}}\right) .
$$

In case of "reabsorption" conditions during the desorption reaction (see Section 2.3 ), $r_{\mathrm{R}}$ is described by an IF condition: IF the system pressure is below the desorption equilibrium pressure, the equations for $r_{\mathrm{R}, \mathrm{des}, \mathrm{MeH}}$ are valid. IF the system is above the absorption equilibrium pressure and IF already more than $1 \%$ of the transformed fraction has been desorbed, $r_{\mathrm{R}}$ is characterized by the equations for $r_{\mathrm{R}, \mathrm{abs}, \mathrm{MeH}} \cdot$

When Darcy's law, $\nabla P_{\mathrm{g}}=-\frac{\mu}{K} \cdot \overrightarrow{v_{\mathrm{g}}}$, is applied for the description of the gas velocity, $\overrightarrow{v_{\mathrm{g}}}$, the equation of the mass balance of the gas phase in terms of gas pressure $P_{\mathrm{g}}$ is given by

$$
\varepsilon \frac{M}{\Re T} \frac{\partial P_{\mathrm{g}}}{\partial t}-\varepsilon \frac{P_{\mathrm{g}} M}{\Re T^{2}} \frac{\partial T}{\partial t}-\nabla\left(\rho_{\mathrm{g}} \frac{K}{\mu} \nabla P_{\mathrm{g}}\right)=-(1-\varepsilon) r_{\mathrm{R}} w t_{\max } \rho_{s}-\dot{m}_{d e s},
$$

where $M$ is the molar mass of $\mathrm{H}_{2}, \mathfrak{R}$ is the real gas constant, $T$ the temperature, $\rho_{\mathrm{g}}$ the density of the gas, $K$ the permeability of the powder bed, $\mu$ the viscosity of $\mathrm{H}_{2}, \varepsilon$ the porosity of the bed, $w t_{\max }$ the maximum hydrogen storage capacity of the material and $\rho_{\mathrm{s}}$ the solid density. $\dot{m}_{d e s}$ refers to the mass of hydrogen that is removed from the reactor, see Section 1.1.2.

For the energy balance of the system, local thermal equilibrium (LTE), $T=T_{\mathrm{g}}=T_{\mathrm{s}}$, is assumed leading to

$$
\begin{aligned}
& {\left[(1-\varepsilon) c_{\mathrm{p}, \mathrm{s}} \rho_{\mathrm{s}}+\varepsilon c_{\mathrm{p}, \mathrm{g}} \rho_{g}\right] \frac{\partial T}{\partial t}=c_{\mathrm{p}, \mathrm{g}} \rho_{\mathrm{g}} \frac{K}{\mu} \nabla P_{\mathrm{g}} \nabla T-\nabla \cdot\left(-\lambda_{\mathrm{eff}} \nabla T\right)} \\
& -(1-\varepsilon) r_{\mathrm{R}} w t_{\max } \rho_{s} \Delta_{\mathrm{R}} H .
\end{aligned}
$$

The expression on the left hand side of Equation 7 refers to the accumulation of enthalpy in the gas as well as in the solid phase with the heat capacity of the gas and solid $c_{\mathrm{p}, \mathrm{s} / \mathrm{g}}$. On the right hand side, convective heat transfer of the gas phase, heat transfer by thermal conduction in the powder and a heat source due to the reaction are accounted for, where $\Delta_{R} H$ is the enthalpy of the desorption reaction. In case of "reabsorption", in analogy to the IF condition for the effective reaction rate mentioned above, another IF condition has been applied on the enthalpy of reaction.

\subsubsection{Initial and boundary conditions}

The initial condition for the temperature of the tank is given by the constraints of a HT-PEM fuel cell, $T_{\mathrm{i}}$ $=T_{\text {steel, } \mathrm{i}}=170{ }^{\circ} \mathrm{C}$, and the initial pressure is set to $P_{\mathrm{i}}=20$ bar. This pressure is below the fuelling pressure of 70 bar, however, as in the first seconds $\mathrm{H}_{2}$ is only released from the void space of the reactor, this behavior is not relevant for the present considerations. Furthermore, in the initial state, both materials are fully in the absorbed state.

For the energy equation, the boundary condition at the center is a symmetry condition. At the outer surface, a heat flux from the steel wall to the heat transfer fluid has been assumed that is characterized by a heat transfer coefficient of $\alpha=600 \mathrm{Wm}^{-2} \mathrm{~K}^{-1}$, compare [11]. The most important boundary condition during desorption experiments, however, is given by the mass flow rate of $\mathrm{H}_{2}$ that 
is removed from the system and consumed by the fuel cell. This flow rate is implemented as a (negative) source term in the gas balance of the system (see Equation (6)), and it causes the characteristic decrease in system pressure that results in the endothermal desorption reaction and the corresponding temperature decrease. Thus, this mass flow rate is a very important variable for the simulations and has to be chosen in a reasonable way. For the present simulations, the storage capacity of the reactor has been related to the storage discharging time in order to be able to compare different scenarios and different reactor designs. E.g., in the present basic case it has been assumed that the storage capacity of the $\mathrm{MeH}$ and the $\mathrm{CxH}$ in a reactor with a length of $1 \mathrm{~m}$ is deploited in $3 \mathrm{~h}$. Thus, the required desorption $\mathrm{H}_{2}$ flow rate $r_{\text {des }}$ is given in $\mathrm{s}^{-1}$ as $1 / 10800 \mathrm{~s}=9.2610^{-5} \mathrm{~s}^{-1}$, and the resulting mass flow rate is calculated as

$$
\dot{m}_{\text {des }}=\rho_{\mathrm{s}} w t_{\text {max }}(1-\varepsilon) \cdot r_{\text {des }} \cdot A_{\text {tube }} \cdot H,
$$

where $A_{\text {tube }}$ refers to the perpendicular cut of tube axis that corresponds to the geometry of the model and the height of the reactor is defined as $H=1 \mathrm{~m}$. For the termination of the simulation, the following condition has been applied: as soon as the pressure reaches a value below 1.7 bar - the minimum working pressure to supply the fuel cell - the simulation is terminated. Besides simulations with a constant desorption $\mathrm{H}_{2}$ flow rate, also simulations with periodic $\mathrm{H}_{2}$ flow rates (thus, varying values of the source term) have been performed, see Section 2.3 .

\section{Results and Discussion}

The general effect of the addition of a $\mathrm{MeH}$ material to a $\mathrm{CxH}$ material in a combination reactor has already been discussed in a previous publication [11] and can be summarized as follows:

- The addition of the $\mathrm{MeH}$ to the $\mathrm{CxH}$ material stabilizes the pressure in the system: As the reation rate of the $\mathrm{MeH}$ is several orders of magnitude higher than the rate of the $\mathrm{CxH}$, the pressure in the system will not fall below the equilibrium pressure of the $\mathrm{MeH}$ material as long as the MeH can desorb hydrogen.

- The efficiency of the hydrogen storage in the $\mathrm{CxH}$ material is improved since, as long as the $\mathrm{MeH}$ is stabilizing the pressure, the $\mathrm{CxH}$ material can desorb at its own desorption rate. Thus, the $\mathrm{MeH}$ is just desorbing as much $\mathrm{H}_{2}$ as to meet the demand of hydrogen for the fuel cell.

- The temperatures in the reactor decrease due to the endothermic reaction. As the $\mathrm{MeH}$ is placed at the center of the tube, where the lowest temperatures appear, this region of the reactor is efficiently used as the $\mathrm{MeH}$ still shows sufficient kinetics even at low temperatures. $\left(<150^{\circ} \mathrm{C}\right)$.

The goal of the present publication is to study these effects in more detail and derive suggestions for future tank design of similar reactors. First, the effect of varying geometries is studied in Section 2.1, and the optimum reactor design for absorption determined in a previous publication is evaluated with respect to desorption constraints. Then, in Section 2.2, the minimum module size for a satisfying desorption performance is discussed, when the effective reaction rates of the materials are known. This minimum module size is important for applications requiring a substantial thermal management, e.g. sufficient heat transfer at a specific temperature level, when a tank is coupled to a HT-PEM fuel cell. Finally, the dynamic performance of a combination reactor is studied when the $\mathrm{H}_{2}$ flow rate shows 


\section{I.Bürger et al.}

a dynamic behavior, and the observed effects are explained by the effective desorption rates of the different materials, see Section 2.3.

\subsection{Optimum reactor design for desorption}

In a previously published study, an optimum geometry for a combination reactor has been determined with respect to a short filling time leading to a reactor with a geometry of $d_{\mathrm{MeH}}=10 \mathrm{~mm}$ and $\xi=1.25$ [12]. In this section, it is now studied whether this radial geometry determined for absorption is also useful for the constraints that apply during desorption operation. Therefore, starting from the optimum absorption geometry, different geometric parameters are varied in the following, where always a scenario with a complete desorption in $3 \mathrm{~h}$ is considered.

\subsubsection{Variation of the ratio $\xi$}

First of all, the effect of varied values for $\xi$ on the desorption performance is studied in analogy to the absorption study [12]. Figure 2 shows the corresponding transformed fraction plot for $\xi$ values of 0.5 to 4 , for a discharging time of $3 \mathrm{~h}$. Additionally, the values for volumetric ratio $\left(\varepsilon_{\mathrm{CXH}}=V_{\mathrm{CxH}} / V_{\text {total }}\right)$, storage capacity and stored $\mathrm{H}_{2}$ per $m$ length of reactor are summarized in Table 1 for the different cases $(A, D$, $E, F)$. In case of absorption there exists a clear optimum regarding the minium fuelling time as it has been shown in a previous publication [12]. In contrast, for the desorption process the decision on an optimum is not clearly defined as there is not only one single criterium that has to be met. For the combination reactor, the optimal value is rather a trade-off between discharging efficiency and $\mathrm{CxH}$ volumetric ratio. For a value of $\xi=0.5$ (green), the discharging efficiency is very high, however, with $\varepsilon_{\mathrm{C} \times \mathrm{H}}=0.56$, the tank mainly consists of $\mathrm{MeH}$ material. On the other hand, for $\xi=4$ (turquoise), the discharging efficiency is very low as the desorption is interrupted early. Therefore, a value of 1.25 (black), which has been the optimum for absorption is also suitable for the discharging process leading to a $\mathrm{CxH}$ fraction of $\varepsilon_{\mathrm{CxH}}=0.8$.

\subsubsection{Variation in $d_{\mathrm{MeH}}$}

Next to a variation of $\xi$, also the radius of the $\mathrm{MeH}$ material $d_{\mathrm{MeH}}$ at the center has been varied from 10 to 5 and $15 \mathrm{~mm}$, and the optimum values for each $\xi$ have been adapted from the analogous absorption simulations. Figure 3 shows the corresponding absolute mass of hydrogen that is desorbed in each case per $m$ length of reactor (compare also Table 1). From this plot it is obvious that in case of the reactor with $d_{\mathrm{MeH}}{ }{ }^{1} 15 \mathrm{~mm}$ (red), the $\mathrm{MeH}$ dominates the combination reactor as more hydrogen is actually stored in the $\mathrm{MeH}(23.5 \mathrm{~g}$, dashes) than in the $\mathrm{CxH}$ ( $16.5 \mathrm{~g}$, solid). In case of the $5 \mathrm{~mm}$ reactor (orange) this ratio is much better with 2.6 to $8.2 \mathrm{~g}$. However, the total mass of $\mathrm{H}_{2}$ stored per m length of reactor is very small. Thus, it can be concluded that for desorption a geometry using $d_{\mathrm{MeH}}=10 \mathrm{~mm}$ (black), shows a good trade off between performance and stored $\mathrm{H}_{2}$ per $\mathrm{m}$.

Summarizing the parameter study on the optimum reactor geometry, it is obvious that the optimum geometry for absorption is also applicable for the desorption process. 


\subsection{Discussion of minimum module size for desorption process}

As it has been concluded in the previous section, a reactor design that is optimal with regards to the absorption process - filling time - is also suitable for a general desorption scenario. However, for the desorption process also the module size of the overall tank can be crucial, as it will be shown in the following.

In this section, the correlation between the effective reaction rates of the materials as well as the discharging time of the storage reactor and the minimum possible reactor module size is discussed. Furthermore, it is introduced how this module size can influence the thermal management of a reactor during desorption operation. As mentioned before, the module size always refers to the mass of hydride that desorbs hydrogen at the same time, thus it is independent of any geometric assumption.

First, two basic scenarios are depicted in Figure 4, in order to explain the effects of different module sizes on the operation procedure. In both cases, a total mass of $5 \mathrm{~kg}_{\mathrm{H} 2}$ is stored in 10 elements of the same dimensions and the reactor is operated for $10 \mathrm{~h}$ until it is compeletely discharged:

I. In the $1^{\text {st }}$ case, 5 (out of 10 ) elements are connected to one module. They are heated up to the nominal operation temperature and operated for the first $5 \mathrm{~h}$. Each element is desorbing hydrogen with a rate of $0.1 \mathrm{~kg}_{\mathrm{H} 2}$ per $\mathrm{h}$ resulting in an overall $\mathrm{H}_{2}$ discharging rate of $0.5 \mathrm{~kg}_{\mathrm{H} 2} \mathrm{~h}^{-1}$ of the whole module. After $5 \mathrm{~h}$, the second module has to be in operation. Therefore, the next 5 identical elements are heated up and the same $\mathrm{H}_{2}$ flow rate is desorbed by the material in this module. So, hydrogen has been delivered at a discharging rate of $0.5 \mathrm{~kg}_{\mathrm{H} 2} \mathrm{~h}^{-1}$ to the fuel cell during $10 \mathrm{~h}$ of operation. In this case, it is possible to use hydride materials with very low effective (desorption) reaction rates, as the size of the two modules is rather big, and the material in the single elements has to desorb $\mathrm{H}_{2}$ at a rather low rate. However, this system is not very flexible concerning cold start ability and/or heat losses, as a very big part of the overall tank has to be heated up and kept at operation temperature at the same time.

II. In the $2^{\text {nd }}$ case, only 1 element is heated up to operation temperature at the same time, so in this case one element refers to one module. Thus, in this module the effective desorption reaction rate of the materials has to be sufficiently high to discharge $0.5 \mathrm{~kg}_{\mathrm{H} 2} \mathrm{~h}^{-1}$ for one hour. Then, the next module is heated up and desorbs the same amount of $\mathrm{H}_{2}$ and so on. Therefore, also in this case a constant $\mathrm{H}_{2}$ discharging rate of $0.5 \mathrm{~kg}_{\mathrm{H} 2} \mathrm{~h}^{-1}$ can be realized while only 1 module is kept at operation temperature at the same time. This kind of configuration is advantageous when a more flexible operation behavior is desired, especially considering the start-up of the system.

From these two cases it is clear that it is desirable to use the smallest possible module size for an enhanced thermal management allowing for a flexible operation of the tank. In the following section, it will be discussed how the minimum module size for a $\mathrm{H}_{2}$ storage reactor can be determined analytically by the effective desorption reaction rate of the material. The considered boundary conditions for these analytical considerations are given by a HT-PEM fuel cell with an assumed temperature of the heat transfer fluid $T_{\mathrm{HTF}}=165-170^{\circ} \mathrm{C}$ and a minimum $\mathrm{H}_{2}$ supply pressure of $0.5-1$ bar and for the material properties of the two reference materials. 


\subsubsection{Analytical Considerations}

For a first guess on the minimum modules size, it is sufficient to consider only the effective reaction rates of the materials. The corresponding procedure can be seen in a plot showing the reaction rate versus the transformed fraction for the considered temperatures and pressures $\left(170{ }^{\circ} \mathrm{C}\right.$ and $0.5-1$ bar). For the reference materials considered in this study, this kind of plot is shown in Figure $5 \mathrm{~A}$ and B. First of all, from this plot it is clear that the reaction rates of the MeH material (B) are 2 to 3 orders of magnitude higher than the reation rates of the considered $\mathrm{CxH}$ material $(A)$, see different scales. The straight lines indicate the required rates for a complete desorption in $t_{\text {des }}=2,3$ or $5 \mathrm{~h}$. As the effective rate of the $\mathrm{MeH}$ is higher than these rates even up to a fully discharged state, it is obvious that the $\mathrm{MeH}$ material can continuously desorb $\mathrm{H}_{2}$ at a high rate. In contrast, the effective reaction rates for the $\mathrm{CxH}$ material are much lower. In this case the material requires at least $5 \mathrm{~h}$ for a complete discharging process, as only in this case the reaction rate is higher than the theoretical rate for a full conversion in $5 \mathrm{~h}\left(\mathrm{a}\right.$ rate of $\left.1 /(5.3600 \mathrm{~s})=5.5610^{-5} \mathrm{~s}^{-1}\right)$. Therefore, for this material, a desorption time of 2 or 3 hours will only lead to $\mathrm{a}_{2}$ release from the $1^{\text {st }}$ desorption step.

Thus, it can be concluded that for the $\mathrm{MeH}$ material, there does not exist a minimum module size from the point of view of reaction rates, as even the total capacity can be released in few seconds. However, for the $\mathrm{CxH}$ material, the size of the modules should be chosen in a way that each module can desorb $\mathrm{H}_{2}$ for at least $5 \mathrm{~h}$ in order to be able to utilize the total capacity of the material. So, comparing Case I and II in Section 2.2.1, each module has to consist of several elements.

Besides the effective reaction rates of the materials at isothermal and isobaric conditions, in a second step it is useful to include more information on the actual reactor design (tube diameters) in the considerations for the minimum module size. As the reactor design will influence the temperature profile appearing in the reactor, this will also influence the overall reactor performance and the assumption of isothermal conditions. E.g., for larger tube diameters the temperature at the center will decrease due to the endothermic reaction, thus, the temperature of the heat transfer fluid will not represent the temperature of the material, consequently the assumption of constant $T$ and $P$ is not valid any more. For the case of an annular ring filled with $\mathrm{CxH}$ material, the temperature decrease between the heat transfer fluid and the temperature $T_{2}$ at the GPSL, can be calculated analytically according to the following equation [17], assuming a constant heat flux due to the endothermal desorption reaction of a constant $\mathrm{H}_{2}$ flow rate from the $\mathrm{CxH}$ material,

$T_{\mathrm{HTF}}-T_{2}=-\frac{\left(\Delta_{\mathrm{R}} H \rho\right)_{\mathrm{CxH}}(1-\varepsilon)}{4 \lambda_{\mathrm{eff}} t_{\mathrm{dis}}}\left(r_{\mathrm{i}}^{2}-d_{\mathrm{MeH}}^{2}\right)+\frac{\left(\Delta_{\mathrm{R}} H \rho\right)_{\mathrm{CxH}}(1-\varepsilon)}{2 \lambda_{\mathrm{eff}} t_{\mathrm{dis}}} d_{\mathrm{MeH}}^{2} \ln \left(\frac{r_{\mathrm{i}}}{d_{\mathrm{MeH}}}\right)$,

where $T_{\mathrm{HTF}}$ and $T_{2}$ are the temperatures of the heat transfer fluid and the GPSL, $\Delta_{\mathrm{R}} H, \rho_{\mathrm{s}}, w t_{\mathrm{CxH}}, \varepsilon$ and $\lambda_{\text {eff }}$ are the reaction enthalpy, the density, the storage capacity, the porosity and the effective thermal conductivity, and $r_{\mathrm{HTF}}$ and $d_{\mathrm{MeH}}$ are the radii of the annulus corresponding to Figure 1 . Furthermore, $t_{\mathrm{dis}}$ is the given discharging time. The calculated temperature decreases for the optimum design determined in the absorption scenario [12] (compare Table 1, A, B, C), are $7.1 \mathrm{~K}, 4.7 \mathrm{~K}$ and $3.5 \mathrm{~K}$ for the complete desorption in $2 \mathrm{~h}, 3 \mathrm{~h}$ and $5 \mathrm{~h}$, respectively. 
Thus, for the $3 \mathrm{~h}$ and $5 \mathrm{~h}$ desorption the temperature decrease is not very prominent $(<5 \mathrm{~K})$ and it can be assumed that the first estimation of the minimum module size using only the effective reaction rate information at constant temperature is correct.

\subsubsection{Simulation results}

The previously introduced analytical considerations showed the challenges during desorption processes for materials with very low effective desorption reaction rates, e.g. $\mathrm{CxH}$ materials. Furthermore, they showed how a first estimate on the minimum possible module size for a combination reactor can be obtained, based on the assumption that the $\mathrm{CxH}$ material is dominating the overall performance. In this section, this initial analytical estimate is analyzed in detail by a discussion of the time dependent desorption simulations of both materials in the combination reactor as well as by a discussion of the final mass of $\mathrm{H}_{2}$ that could be desorbed in the different cases.

Figure 6A shows the transformed fraction of $\mathrm{MeH}$ and $\mathrm{CxH}$ versus time profiles for the simulated cases, where the total stored $\mathrm{H}_{2}$ capacity is desorbed in $2 \mathrm{~h}, 3 \mathrm{~h}$ and $5 \mathrm{~h}$ (compare Table $1, \mathrm{~A}, \mathrm{~B}, \mathrm{C}$ ). Regarding the geometry, the optimum geometry obtained from the 1D simulations for absorption is considered with $d_{\mathrm{CXH}}=10 \mathrm{~mm}$ and $\xi=1.25$, and the length of one module is defined as $1 \mathrm{~m}$.

The time dependent behavior is in all three cases quite similar and can be described as follows: in the beginning the straight lines which indicate the mass $\mathrm{H}_{2}$ desorbed by the $\mathrm{CxH}$ material increase while the dashed lines referring to the MeH material stay at a very low level. Thus, the majority of $\mathrm{H}_{2}$ is desorbed by the $\mathrm{CxH}$ material. Then, towards the end of each scenario, the effective reaction rate of the $\mathrm{CxH}$ is slowing down and the $\mathrm{MeH}$ material starts to desorb $\mathrm{H}_{2}$ filling the gap to the required $\mathrm{H}_{2}$ flow rate for the fuel cell. The same effect can be seen from Figure $6 \mathrm{~B}$ where the temperature at the GPSL, $T_{2}$ (dashes), as well as the temperature at the center, $T_{1}$ (solid), are plotted versus time for the same three cases. First, the temperature in the center follows the equilibrium of the $\mathrm{CxH}$ indicating that mainly $\mathrm{CxH}$ material is desorbing hydrogen. Then, more $\mathrm{H}_{2}$ has to be desorbed by the $\mathrm{MeH}$ material resulting in a temperature decrease to the equilibrium temperature of the $\mathrm{MeH}$ material, and the temperature $T_{1}$ in the center starts to vary significantly from the temperature at the GPSL, $T_{2}$.

This behavior of the three different desorption cases is in accordance with Figure 5, that has been discussed above: in all three cases, towards the termination of the simulation the $\mathrm{MeH}$ is compeletely discharged with a wtrac of 0.009 at $165^{\circ} \mathrm{C}$ (dashed lines), as the effective reaction rate of this material is very high even at the applied pressures and temperature. However, for the discharge of the $\mathrm{CxH}$ material different values are obtained: in case of a discharging within $2 \mathrm{~h}$ and $3 \mathrm{~h}$, just $2 \mathrm{wt} . \%$ and 2.4 wt.\% can be desorbed corresponding mainly to the $1^{\text {st }}$ desorption step. Only for the case of a desorption for $5 \mathrm{~h}$ the full $\mathrm{H}_{2}$ capacity of $3.2 \mathrm{wt} . \%$ can be reached. Linking these findings to the general exemplary cases in Section 2.2.1, it is obvious that for a discharging of the reaction in 2 or $3 \mathrm{~h}$, the currently used module size is too small to completely discharge the reactor for the effective reaction rate of the reference materials. Therefore, if a complete discharging is desired, either the module size should be increased or the discharging rate reduced (to e.g. $5 \mathrm{~h}$ ).

Concluding this section it can be stated that the analytical considerations and the simulated results agree very well: The minimum discharging rate from $3 \mathrm{~h}$ for the complete $1^{\text {st }}$ desorption step and $5 \mathrm{~h}$ for a full $2^{\text {nd }}$ step desorption that have been predicted by the analytical considerations have been 


\section{I.Bürger et al.}

confirmed in detail by the 1D simulations. For a discharging process within $2 \mathrm{~h}$, significantly less $\mathrm{H}_{2}$ could be desorbed. Here a clear deviation from the analytical estimation is obtainded since it predicted a very similar behavior to the discharging within $3 \mathrm{~h}$. However, in this case, the more prominent temperature decrease - that has already been predicted analytically - deteriorates the performance, as it can be clearly seen from Figure $6 \mathrm{~B}$.

Thus, the analytical considerations presented in Section 2.1.1 can be useful to understand the correlations between the module size of a reactor and its desorption performance at a given discharging rate for materials with given desorption rates. This fact can especially be interesting for tank applications requiring a substantial thermal management, as it is the case for coupling a solid state hydrogen storage tank to a HT-PEM fuel cell.

\subsection{Simulations with varying loads}

In the previous section, it has been introduced why small module sizes can be an important issue for technically relevant storage tanks. This was done based on the assumption of constant discharging rates. In this section, more realistic boundary conditions, for e.g. a scenario where the tank is coupled to a HT-PEM fuel cell, will beconsidered. Therefore, besides scenarios with constant discharging rates simulating a constant power output of the fuel cell, the behavior of a tank during varying loads is of high practical importance, e.g., in a driving scenario this can correspond to going uphill or going downhill [18].

In order to understand the performance of a combination reactor during dynamic loads and especially the effect of the additional $\mathrm{MeH}, 3$ different scenarios are simulated using the basic geometry with $d_{\mathrm{MeH}}$ $=10 \mathrm{~mm}$ and $\xi=1.25$ (see Table 1, A):

- The first scenario (I) is the basic case for the optimum geometry with a discharging time of $3 \mathrm{~h}$, as it has been used also in the previous sections.

- The second scenario (II) refers to the same discharging time, however, in this case the rate is not constant but it is varied: for $30 \mathrm{~s}, 6$ times the base load is discharged and for the following $450 \mathrm{~s}$, the load is reduced by a factor of 10 to 0.67 times the base load.

- The third scenario (III) refers again to the same discharging time, but now the rate is varied between $30 \mathrm{~s}$ and $450 \mathrm{~s}$ from 0.53 to 8 , so by a factor of 15 .

Figure 7 shows the discharging rates for the three different cases together with the rates versus transformed fraction plot of the $\mathrm{CXH}$ material at given temperature and pressure $\left(T_{\mathrm{HTF}}=170{ }^{\circ} \mathrm{C}\right.$ and $P>$ 1.7 bar, compare Figure $5 \mathrm{~A}$ ). From this plot it becomes obvious that using the constant discharging rate of Scenario I (blue straight line), the $1^{\text {st }}$ desorption step of the $\mathrm{CxH}$ material can in principle be fully discharged as the required flow rate is below the possible desorption flow rate up to $60 \%$ transformed fraction. In Scenario II, the peak rates should be acceptable up to a transformed fraction of approx. $30 \%$, thus in this case approx. half of the $1^{\text {st }}$ desorption step should be available for this varying load case. Finally, for Scenario III, the peak loads exceed the possible desorption rates of the $\mathrm{CxH}$ material even at very low transformed fractions. Thus, in a pure $\mathrm{CxH}$ reactor with the present geometry and module size, the material would not be able to keep up the required discharging flow rate from the fuel cell even from the beginning - even for ideal (isothermal and isobaric) conditions. 
For scenarios with varying discharging rates, the analytical considerations reflecting mainly the $\mathrm{CxH}$ material desorption rates are insufficient to capture the final behavior. Therefore, detailed simulations are required that take the simultanious reactions of both materials into account. Figure 8 shows the results of the time dependent simulations of the three scenarios using the optimum geometry of the combination reactor (see Table 1, A). In Figure 8A, the system pressure is plotted versus time for the three scenarios. Obviously, in Scenarios II and III, the pressure is varying periodically due to the periodic discharging rate. The intensity of this fluctuation depends on the intensity of the different discharging rates, thus for Scenario III (green, dots) the variations are more significant than for Scenario II (red, dashes). Furthermore, it is obvious that in all three scenarios the time until the experiment is interrupted is very similar. This is surprising as the rate during peak loads in Scenario III clearly exceeds the possible effective desorption rate of the $\mathrm{CxH}$ material, see discussion above. This behavior is due to the additional $\mathrm{MeH}$ material in the combination reactor and it clearly shows the advantages on the dynamic behavior of such a combination reactor: even when in a scenario the peak loads exceed the maximum desorption rates of the $\mathrm{CxH}$ material, the $\mathrm{MeH}$ material can additionally desorb and thus stabilize the system pressure. Furthermore, as the system pressure is stabilized, it is possible that in all three cases the same amount of $\mathrm{H}_{2}$ is desorbed from both materials as it is shown in Figure $8 \mathrm{~B}$, where the mass of desorbed $\mathrm{H}_{2}$ is plotted: in all three cases not only the MeH but also the $\mathrm{CxH}$ material desorbs $\mathrm{H}_{2}$ up to the same value.

In the following, the two parallel reactions are discussed in more detail. It will be shown that the MeH material is not only desorbing extra hydrogen during peak loads, but it is also able to "reabsorb" hydrogen during low loads. Thus, the "buffering" function of the $\mathrm{MeH}$ material is not only available once, but it can be recharged. Figure 9 shows a detail of the system pressure (red) as well as the equilibrium pressures for desorption of the $\mathrm{CxH}$ (black dots) and the $\mathrm{MeH}$ (grey dots) and for absorption for the MeH (grey dashes) for Scenario III. From this graph it is obvious that the system pressure never falls below the desorption pressure of the $\mathrm{MeH}$ material as this is desorbing sufficiently fast to keep a constant system pressure. Furthermore, during low load conditions the system pressure never exceeds the absorption equilibrium pressure of the $\mathrm{MeH}$ material indicating that the material "reabsorbs" hydrogen. Since the system pressure is constantly below the desorption equilibrium pressure of the $\mathrm{CxH}$ material, the $\mathrm{CxH}$ desorbs continuously thereby also supplying hydrogen for the "reabsorption" in the $\mathrm{MeH}$. The "reabsorption" is possible until approx. $3600 \mathrm{~s}$, then the system pressure does not reach the required absorption pressure of the $\mathrm{MeH}$ anymore. The same fact is shown in Figure 10, where a detail of the desorbed mass $\mathrm{H}_{2}$ is plotted versus time only for the $\mathrm{MeH}$ material. Here, it can be clearly seen that the desorbed mass of $\mathrm{H}_{2}$ in the MeH material is decreasing during low loads and - during the first part - increasing during peak loads.

In summary it can be concluded that especially Scenarios II and III clearly show the advantages of the combination reactor concept during a dynamic desorption scenario: even when the required peak discharging rate exceeds the possible effective desorption rate of the $\mathrm{CxH}$ material, it is possible to show a satisfying performance on a reactor level. Thus, as long as the required discharging hydrogen rate can be on average supplied by the $\mathrm{CxH}$ material in a given geometry and module size, even much higher peak discharging rates can be tolerated in a combination reactor as the $\mathrm{MeH}$ material can desorb and reabsorb sufficiently fast. 


\section{I.Bürger et al.}

Coming back to the discussion on the minimum module size in Section 2.1, it is obvious that the addition of some $\mathrm{MeH}$ to the $\mathrm{CxH}$ material can decrease the required module size for a pure $\mathrm{CxH}$ tank and thus increase the flexibility of the tank. Especially for the start-up phase or during mode changes in the operation, that require a substantial thermal management, a reactor with a suitable combination of materials can improve the overall performance.

\section{Conclusions}

In the present publication, the desorption performance of different configurations of a combination reactor based on a reference metal hydride and a reference complex hydride have been studied using analytical methods and simulations of a 1D model using the software COMSOL.

First, a sensitivity study of the desorption performance has been performed by varying the ratio between the $\mathrm{MeH}$ and the $\mathrm{CxH}$ as well as the radius of the inner $\mathrm{MeH}$ tube starting from the previously determined optimal absorption geometry. Both studies indicated, that the optimal absorption geometry is also suitable for the given desorption conditions.

Second, based on generic operation conditions, the influence of the module size of a reactor on the required thermal management during operation was analysed. Then, the minimal module size of a reactor has been discussed when a certain discharging time is required and the effective desorption reaction rates characterizing the $\mathrm{CxH}$ material are known. As the rates of the present reference material at $165^{\circ} \mathrm{C}$ and 1 bar are quite low, very large modules are required in order to be able to deliver sufficient hydrogen. Thus, for these materials, the thermal management of the overall tank will be challenging.

Finally, the desorption process has also been studied for varying loads, e.g. for a load variation by a factor of 10 and 15. In this case it was shown that the combination reactor is advantageous as the $\mathrm{MeH}$ material was able to buffer and reabsorb hydrogen during peak and low loads, respectively, leading to smaller possible module sizes than analytically expected. Therefore, based on the combination principle the desorption performance on a reactor level can be better than indicated by the effective desorption rates of the respective $\mathrm{CxH}$ material.

\section{Acknowledgements}

The research leading to these results has received funding from the European Union's Seventh Framework Programme (FP7/2007-2013) for the Fuel Cells and Hydrogen Joint Technology Initiative under grant agreement no. 256653.

M.B. would like to thank the German Academic Exchange Service (DAAD) for the DLR-DAAD Research Fellowship. 


\section{I.Bürger et al.}

\section{Figures}

Figure 1: Schema of the modelled 1D geometry of an axisymmetric tubular reactor.

Figure 2: Mass of $\mathrm{H}_{2}$ desorbed by the $\mathrm{MeH}$ material (dashes) and the $\mathrm{CxH}$ material (solid line) for a desorption scenario at $170{ }^{\circ} \mathrm{C}$ using a complete desorption in $3 \mathrm{~h}$, (compare Table 1, scenario: A, D, E, F). $\xi$ varies from 0.5 (green) to 1.25 (opt, black), 2 (blue) and 4 (turquoise).

Figure 3: Desorption scenario at $170{ }^{\circ} \mathrm{C}$ with $\xi=1.25$ and $d_{\mathrm{MeH}}$ varies from $5 \mathrm{~mm}$ (orange) to $10 \mathrm{~mm}$ (black) and $15 \mathrm{~mm}$ (red), (compare Table 1, scenario: A, G, H). Mass of hydrogen desorbed by the $\mathrm{MeH}$ (dashes) and the $\mathrm{CxH}$ (solid) in $\mathrm{kg}$ per m length of reactor.

Figure 4: Effect of different module sizes on the flexibility of an overall hydride tank system during desorption.

Figure 5: Effective reaction rates versus transformed fraction for $165^{\circ} \mathrm{C}$ and 0.5 bar (solid) or 1 bar (dashed line). A: Reference $\mathrm{CxH}$ material: $2 \mathrm{LiNH}_{2}-1.1 \mathrm{MgH}_{2}-0.1 \mathrm{LiBH}_{4}-3 w \mathrm{t} \% \mathrm{ZrCoH}_{3} \mathrm{~B}$ : Reference MeH material: $\mathrm{LaNi}_{4.3} \mathrm{Al}_{0.4} \mathrm{Mn}_{0.3}$.

Figure 6: Desorption scenario at $170{ }^{\circ} \mathrm{C}$ using the optimal absorption geometry and $r_{\text {des }}$ for a complete desorption in $2 \mathrm{~h}$ (red), $3 \mathrm{~h}$ (black) and $5 \mathrm{~h}$ (blue), (compare Table 1, scenario: A, B, C). A: Mass of $\mathrm{H}_{2}$ desorbed by the $\mathrm{CxH}$ (solid) and $\mathrm{MeH}$ (dashes). B: Temperature $T_{1}$ (solid) and $T_{2}$ (dashes).

Figure 7: Discharging rates for the three different scenarios together with the desorption rate versus the transformed fraction of the reference $\mathrm{CxH}$ material. Complete desorption in $3 \mathrm{~h}$ (solid, blue), varying load varying by a factor of 10 between low and high load (dash, red) and varying load varying by factor of 15 (dot, green). Arrows indicate max. possible transformed fraction for each maximum rate.

Figure 8: Desorption scenario for the three different scenarios: Complete desorption in $3 \mathrm{~h}$ (solid, blue), varying load by a factor of 10 between low and high load (dash, red) and varying load by a factor of 15 (dot, green). A: system pressure. B: mass $\mathrm{H}_{2}$ desorbed by $\mathrm{MeH}$ material (turquoise, orange, light green) and mass $\mathrm{H}_{2}$ desorbed by $\mathrm{CxH}$ material (blue, red and green).

Figure 9: Detail of Scenario II. System pressure (red, solid), desorption equilibrium pressure of the $\mathrm{CxH}$ (black, dot), desorption equilibrium pressure of the $\mathrm{MeH}$ (grey, dot) and absorption equilibrium pressure of the $\mathrm{MeH}$ (grey, dash).

Figure 10: Detail of mass $\mathrm{H}_{2}$ desorbed by Meh material for the desorption scenarios shown in Figure 8. Turquoise: Scenario I, orange: Scenario II, light green: Scenario III. 


\section{I.Bürger et al.}

\section{Tables}

Table 1: Overview of the simulated geometries / scenarios. 
I.Bürger et al.

References

[1] Eberle U, Felderhoff M, Schüth F. Chemical and Physical Solutions for Hydrogen Storage. Angew. Chemie 2009;48(36):6608-30.

[2] Züttel A, Remhof A, Borgschulte A, Friedrichs O. Hydrogen: the future energy carrier. Philos. Trans. A. Math. Phys. Eng. Sci. 2010;368(1923):3329-42.

[3] Weidenthaler C, Felderhoff M. Solid-state hydrogen storage for mobile applications: Quo Vadis? Energy Environ. Sci. 2011;4(7):2495.

[4] Kurtz J, Ainscough C, Simpson L, Caton M. Hydrogen Storage Needs for Early Motive Fuel Cell Markets. 2012.

[5] Klebanoff L, Pratt J, Johnson T, Arienti M, Shaw L, Moreno M. Analysis of H2 Storage Needs for Early Market Non-Motive Fuel Cell Applications. 2012.

[6] Sakintuna B, Lamari-Darkrim F, Hirscher M, Lamaridarkrim F. Metal hydride materials for solid hydrogen storage: A review. Int. J. Hydrogen Energy 2007;32(9):1121-40.

[7] Jain IPP, Jain P, Jain A. Novel hydrogen storage materials: A review of lightweight complex hydrides. J. Alloys Compd. 2010;503(2):303-39.

[8] Klebanoff LE, Keller JO. 5 Years of hydrogen storage research in the U.S. DOE Metal Hydride Center of Excellence (MHCoE). Int. J. Hydrogen Energy 2013;38(11):453376.

[9] Fichtner M. Conversion materials for hydrogen storage and electrochemical applications_Concepts and similarities. J. Alloys Compd. 2011;509:S529-S534.

[10] Bürger I, Komogowski L, Linder M. Advanced reactor concept for complex hydrides: hydrogen absorption from room temperature. Int. J. Hydrogen Energy 2014;39:7030 41.

[11] Bürger I, Luetto C, Linder M. Advanced reactor concept for complex hydrides: hydrogen desorption at fuel cell relevant boundary conditions. Int. J. Hydrogen Energy 2014;39:7346-55.

[12] Bhouri M, Bürger I, Linder M. Optimization of hydrogen charging process parameters for an advanced complex hydride reactor concept. Int. J. Hydrogen Energy 2014;39(31):17726-39.

[13] Pfeifer P, Wall C, Jensen O, Hahn H, Fichtner M. Thermal coupling of a high temperature PEM fuel cell with a complex hydride tank. Int. J. Hydrogen Energy 2009;34(8):3457-66.

[14] Urbanczyk R, Peil S, Bathen D, Heßke C, Burfeind J, Hauschild K, et al. HT-PEM Fuel Cell System with Integrated Complex Metal Hydride Storage Tank. Fuel Cells 2011;11(6):911-20. 
[15] Weiß-Ungethüm J, Bürger I, Schmidt N, Linder M, Kallo J. Experimental investigation of a liquid cooled high temperature proton exchange membrane (HT-PEM) fuel cell coupled to a sodium-alanate tank. Int. J. Hydrogen Energy 2014;39:5931-41.

[16] Bürger I, Hu JJ, Vitillo JG, Kalantzopoulos GN, Deledda S, Fichtner M, et al. Material properties and empirical rate equations for hydrogen sorption reactions in 2 LiNH2 1.1 MgH2 - 0.1 LiBH2 - 3 wt.\% ZrCoH3. Int. J. Hydrogen Energy 2014;39:8283-92.

[17] Corgnale C, Hardy BJ, Tamburello DA, Garrison SL, Anton DL. Acceptability envelope for metal hydride-based hydrogen storage systems. Int. J. Hydrogen Energy 2012;37(3):2812-24.

[18] MacDonald BD, Rowe AM. Experimental and numerical analysis of dynamic metal hydride hydrogen storage systems. J. Power Sources 2007;174(1):282-93. 
Table 1: Overview of the simulated geometries / scenarios.

\begin{tabular}{|c|c|c|c|c|c|c|c|c|}
\hline & Scenario & $\begin{array}{l}d_{\mathrm{MeH}} \\
\mathrm{mm}\end{array}$ & $\begin{array}{l}d_{\mathrm{SSS}} \\
\mathrm{mm}\end{array}$ & $\begin{array}{l}\xi \\
-\end{array}$ & $\begin{array}{c}\varepsilon_{\mathrm{C} \times \mathrm{H}} \\
-\end{array}$ & $\begin{array}{c}t_{\text {dis }} \\
\mathrm{h}\end{array}$ & $\begin{array}{c}m_{\mathrm{MeH}} \\
\text { g per m length }\end{array}$ & $\begin{array}{c}m_{\mathrm{CxH}} \\
\text { g per m length }\end{array}$ \\
\hline \multirow{3}{*}{ 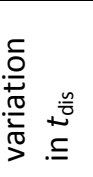 } & A & 10 & 2.0 & 1.25 & 0.80 & 3 & 10.5 & 12.6 \\
\hline & $B$ & 10 & 2.0 & 1.25 & 0.80 & 2 & 10.5 & 10.1 \\
\hline & C & 10 & 2.0 & 1.25 & 0.80 & 5 & 10.5 & 16.4 \\
\hline \multirow{3}{*}{ 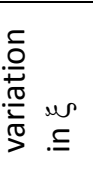 } & D & 10 & 1.4 & 0.50 & 0.56 & 3 & 10.5 & 13.6 \\
\hline & $E$ & 10 & 2.7 & 2.00 & 0.89 & 3 & 10.5 & 11.3 \\
\hline & $\mathrm{F}$ & 10 & 4.5 & 4.00 & 0.96 & 3 & 10.5 & 7.5 \\
\hline \multirow{2}{*}{ 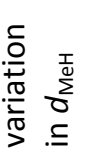 } & G & 5 & 1.6 & 2.50 & 0.92 & 3 & 2.6 & 8.2 \\
\hline & $\mathrm{H}$ & 15 & 2.5 & 0.83 & 0.70 & 3 & 23.5 & 16.5 \\
\hline
\end{tabular}


Figure 1: Scheme of the modelled 1D geometry of an axisymmetric tubular reactor.

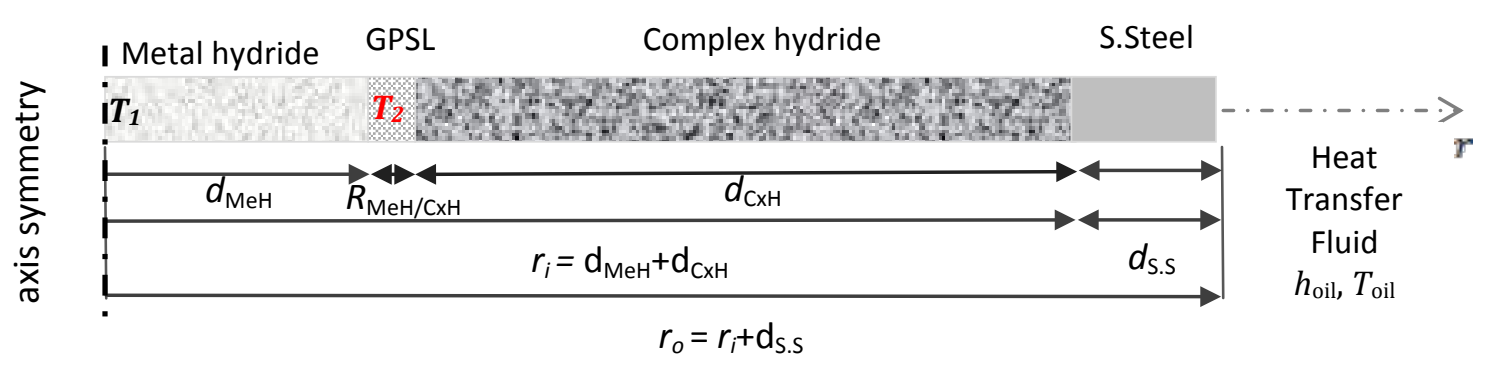


Figure 2

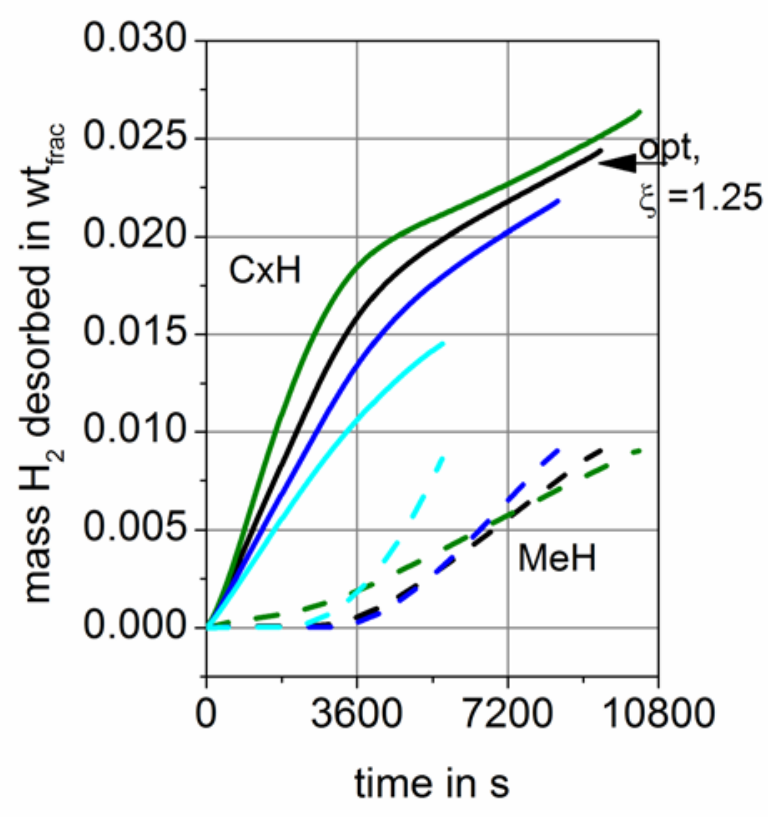


Figure 3:

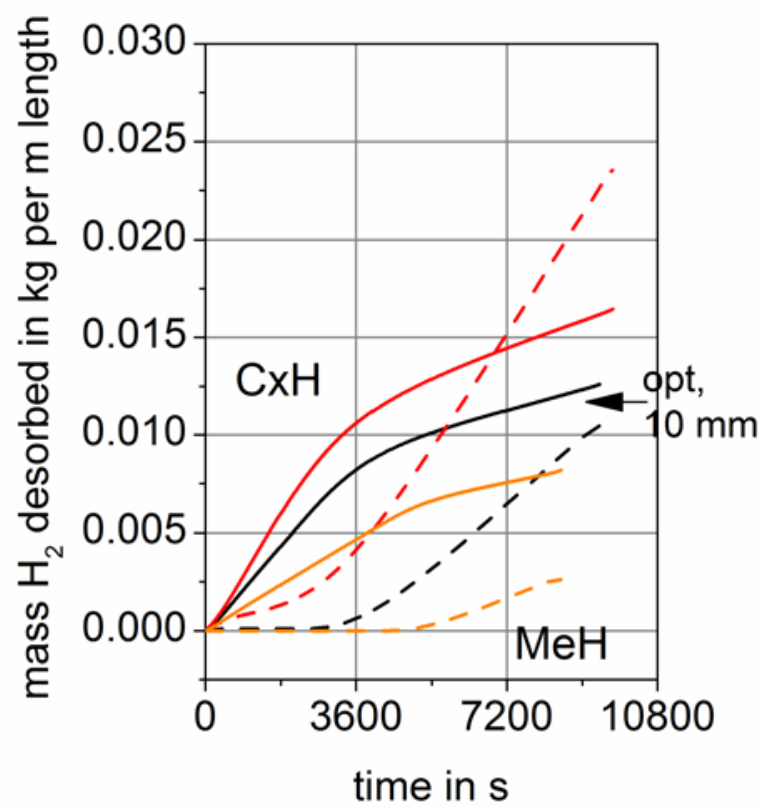


Figure 4:

I: For material with low reaction rate: 5 elements are connected to 1 module

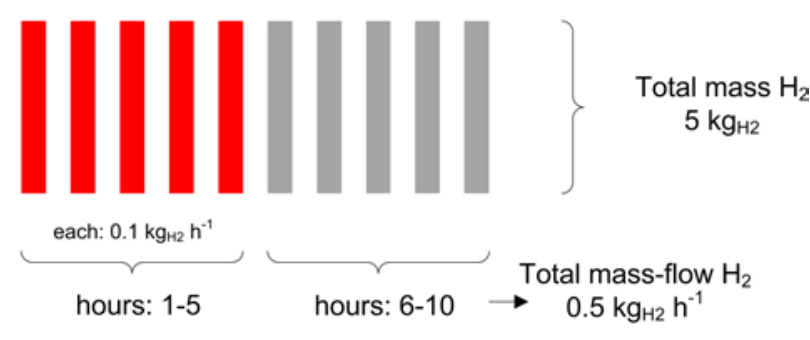

II: For material with high reaction rate: 1 element is 1 module

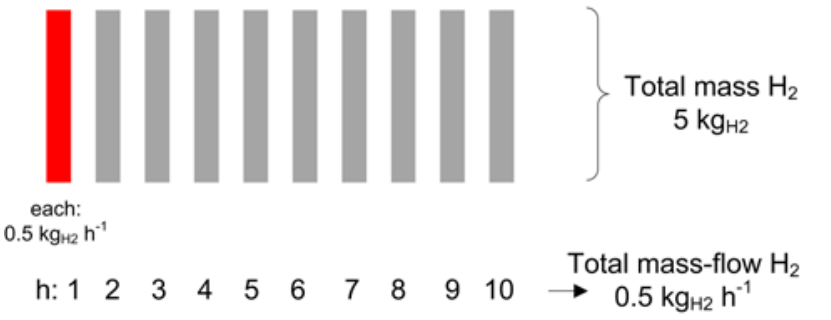


Figure 5:

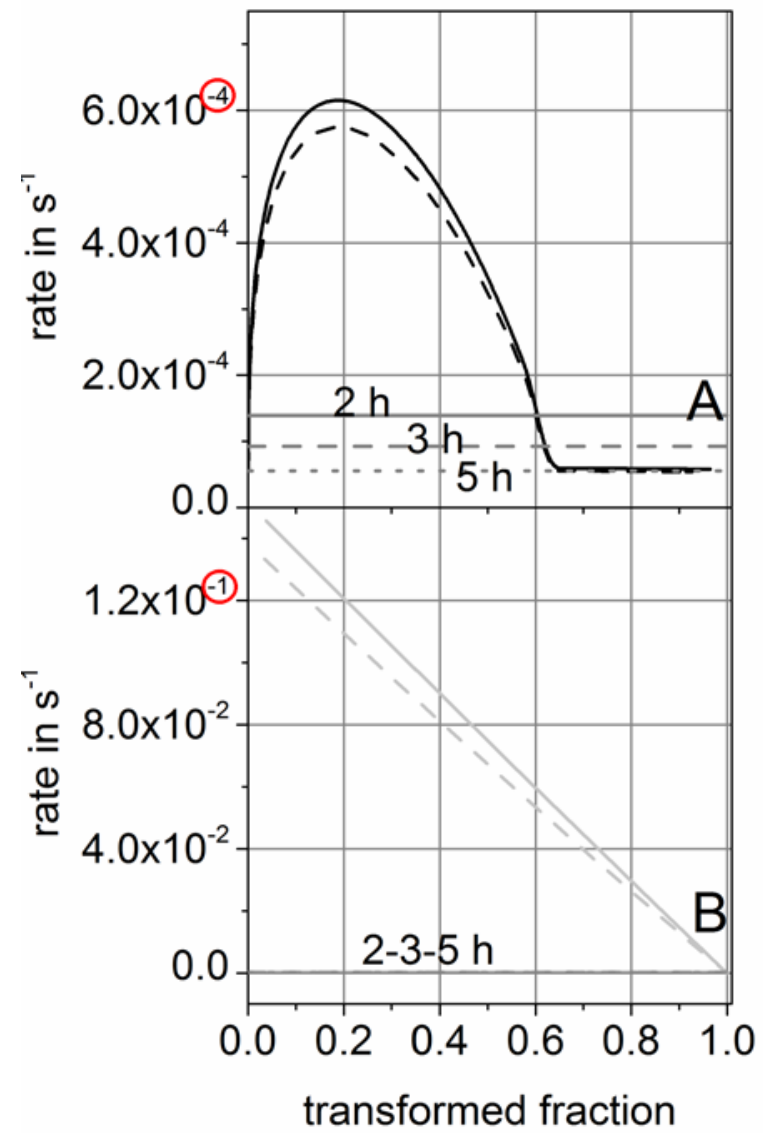


Figure 6:

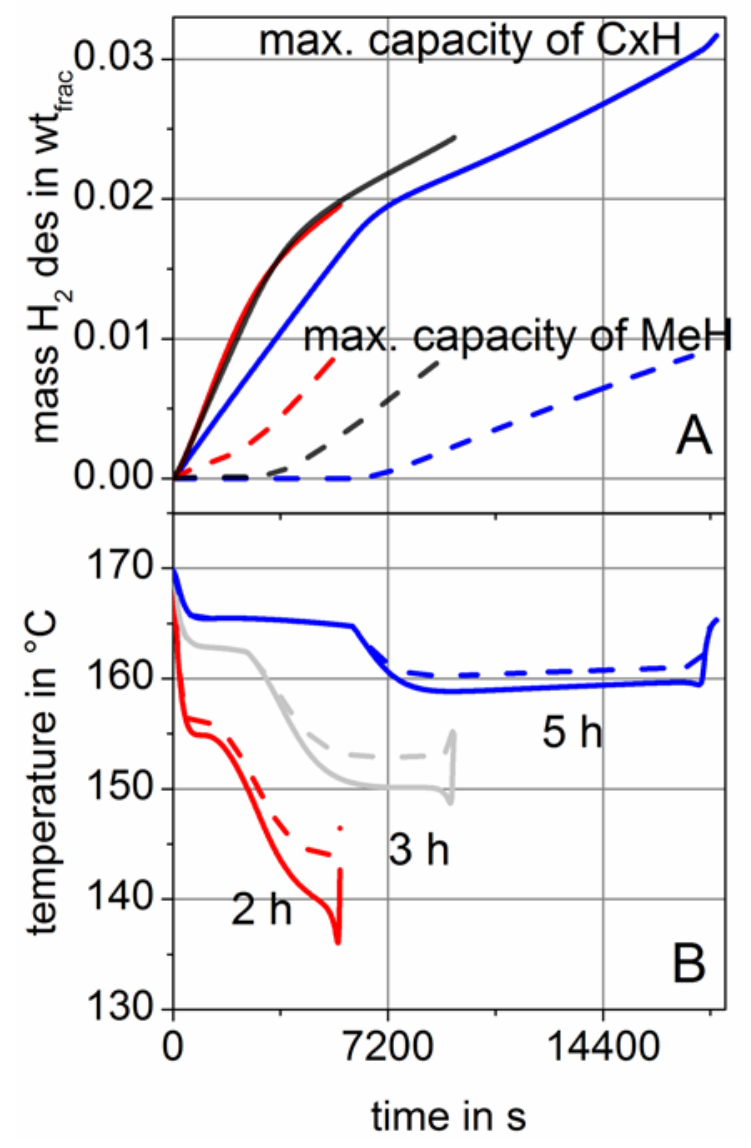


Figure 7:

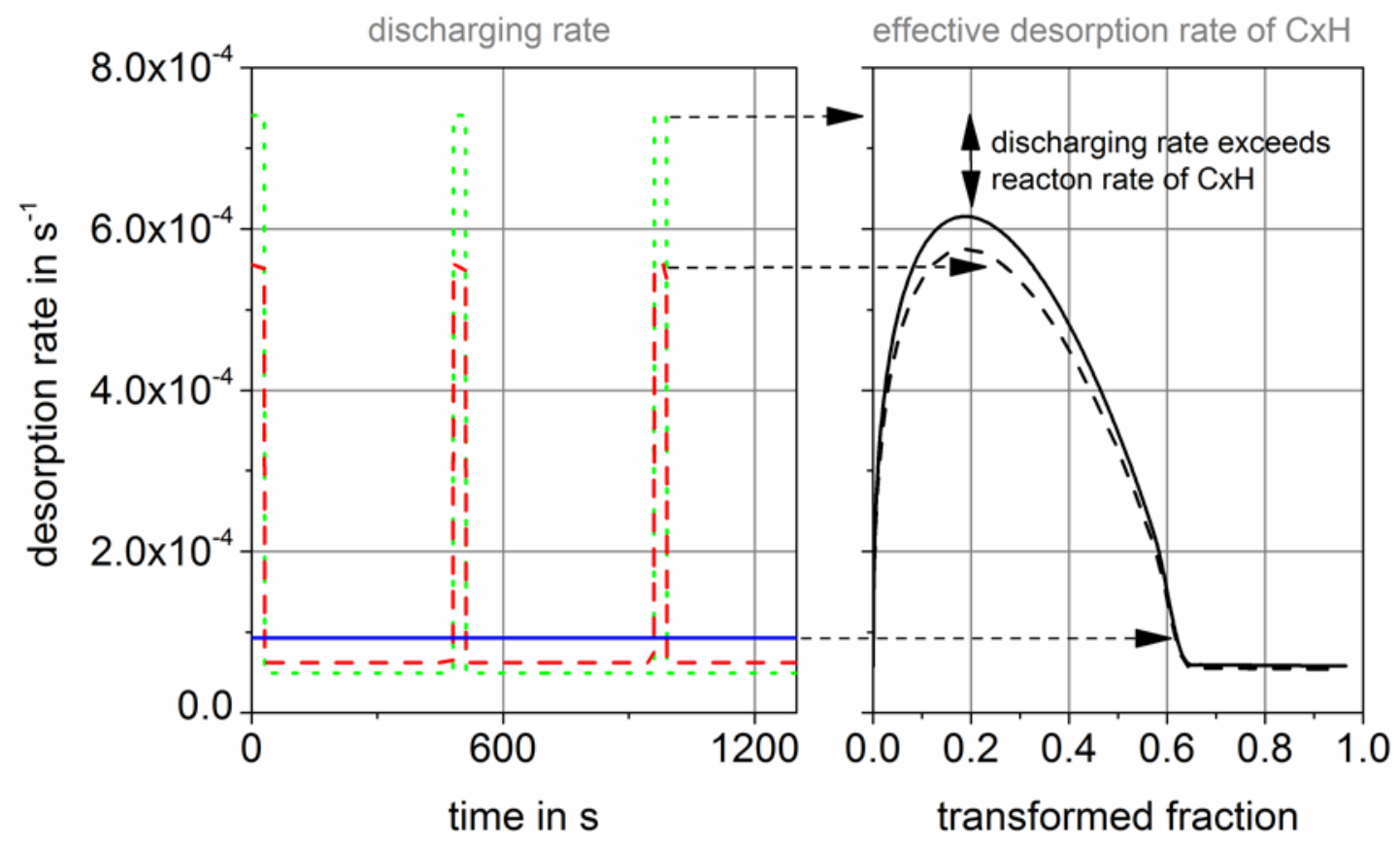


Figure 8:

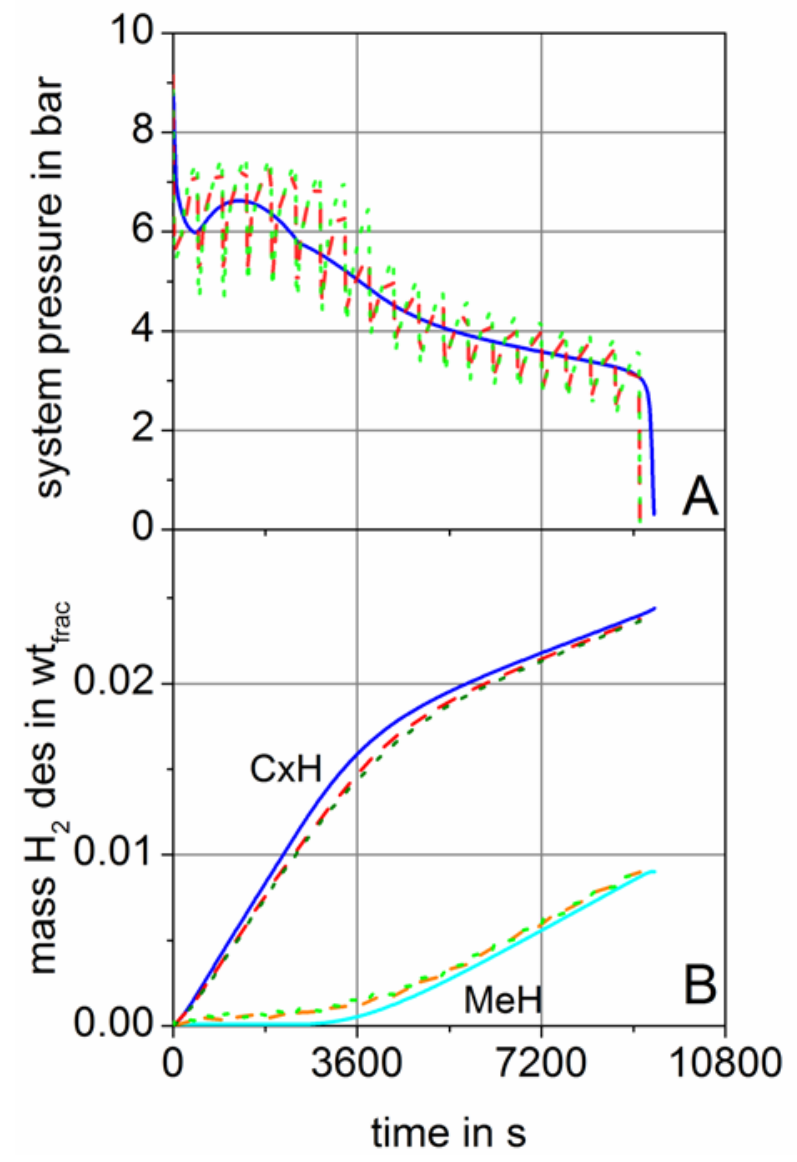


Figure 9:

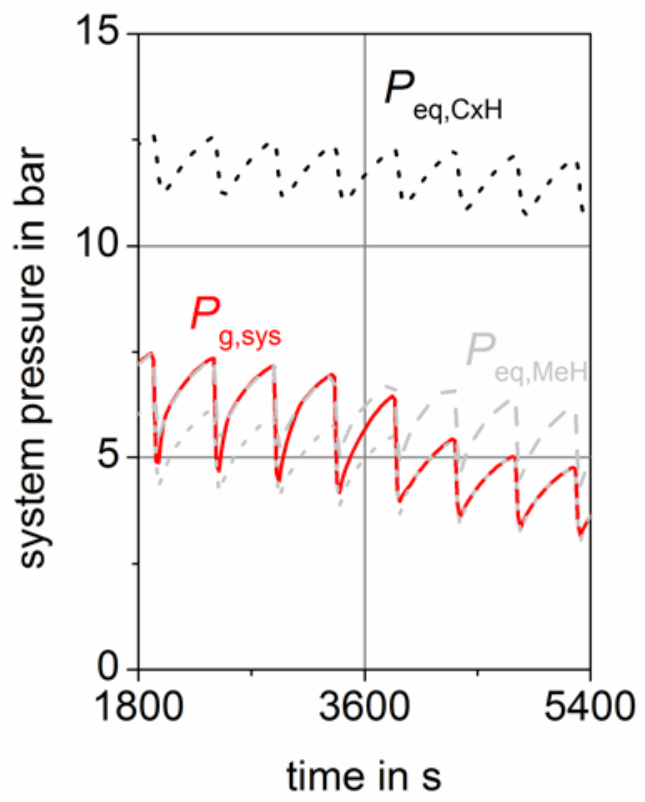


Figure 10:

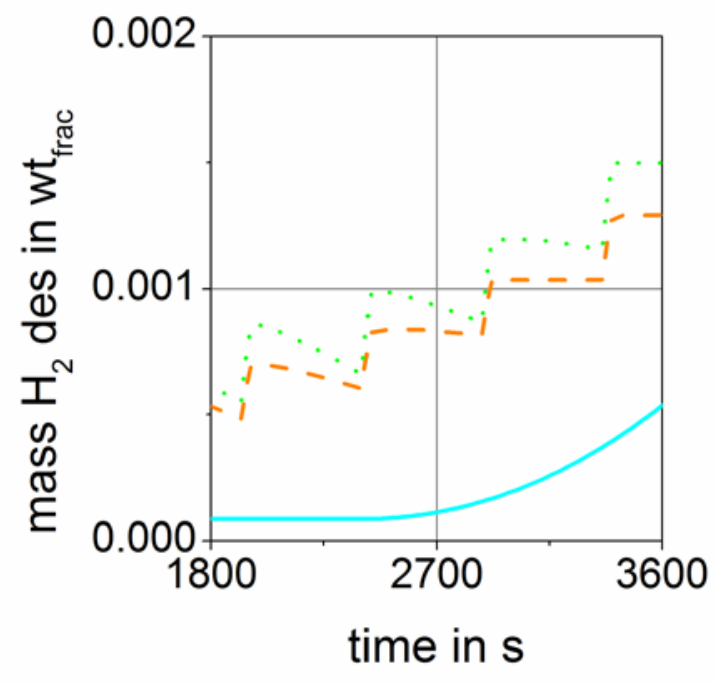

